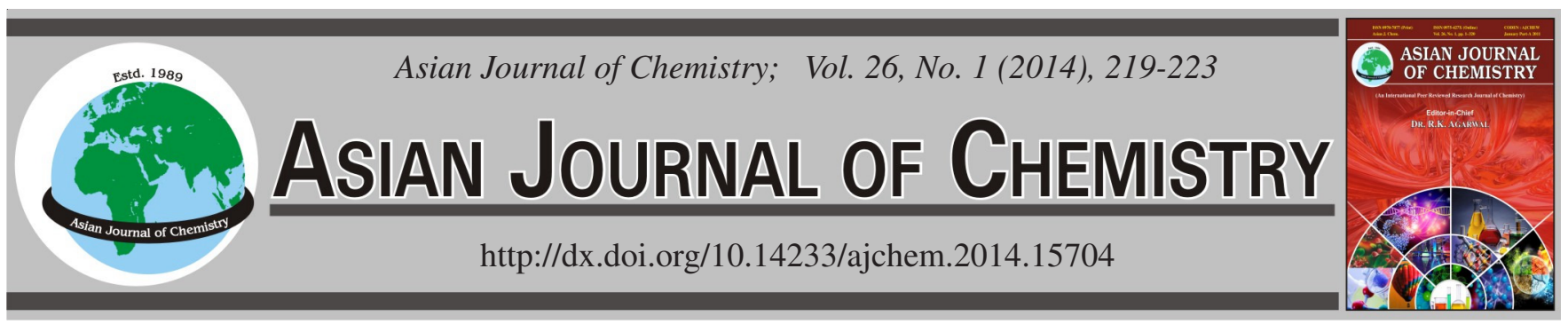

\title{
Simultaneous Determination of Mercury and Antimony in Lead-Base Alloys \\ by Hydride Generation-Double Channel Atomic Fluorescence Spectrometry with Solid-phase Extraction Using Amberlite XAD-16 Resin Micro-column
}

\author{
WeINA ZHANG ${ }^{1, *}$ and TAICHENG DuAN ${ }^{2}$
}

${ }^{1}$ College of Chemistry, Jilin Normal University, Siping, P.R. China

${ }^{2}$ State Key Laboratory of Electroanalytical Chemistry, Changchun Institute of Applied Chemistry, Chinese Academy of Sciences, Changchun, P.R. China

*Corresponding author: Email: nana820616@yahoo.com.cn

Received: 29 April 2013;

Accepted: 20 August 2013;

Published online: 26 December 2013;

AJC-14508

\begin{abstract}
The simultaneous determination of inorganic mercury and antimony was evaluated by the application in lead-base alloys through solidphase extraction (SPE) coupled with hydride generation-double channel atomic fluorescence spectrometry (HG-DC-AFS) using a separation/ preconcentration step on an Amberlite XAD-16 resin packed column. The high selective SPE was based on the similar properties between non-polar resins and molecular covalent compounds e.g., $\mathrm{HgBr}_{2}$ and $\mathrm{SbBr}_{3}$ formed in concentrated $\mathrm{H}_{2} \mathrm{SO}_{4}$ and $\mathrm{HBr}_{\text {media. }}$ Various experimental conditions affecting the solid-phase extraction and determination of the analytes had been investigated. Under the optimized conditions, the limits of detection of $0.17 \mu \mathrm{g} \mathrm{L} \mathrm{L}^{-1}$ for $\mathrm{Hg}(\mathrm{II})$ and $1.66 \mu \mathrm{g} \mathrm{\textrm {L } ^ { - 1 }}$ for $\mathrm{Sb}(\mathrm{III})$ were obtained. The precisions (RSD) for seven replicate measurements of $20 \mu \mathrm{g} \mathrm{L} \mathrm{L}^{-1} \mathrm{Hg}$ (II) and $\mathrm{Sb}(\mathrm{III})$ were 0.37 and $2.9 \%$, respectively. The developed method was validated by spike test and was applied to the separation/ preconcentration of $\mathrm{Hg}$ and $\mathrm{Sb}$ from two lead-base alloys matrices.
\end{abstract}

Keywords: Hydride generation, Solid-phase extraction, Atomic fuorescence spectrometry, XAD-16 resin.

\section{INTRODUCTION}

Lead-base alloys can be used as protection materials for radioactivity works owing to their property of against penetration of X-ray and $\gamma$-ray. But trace impurities in lead-base alloys such as inorganic mercury can reduce the corrosion resistance. On the contrary, some added metals can improve their mechanical properties, e.g., the addition of antimony can improve the framework of crystal particle, enhance intensity, restrain danger of bismuth and improve corrosion resistance. Thus, an establishment of sensitive and accurate method to determine these elements simultaneously in these alloys is required.

But direct simultaneous determination for mercury and antimony is difficult due to their volatilization and interferences of complex matrix in alloys. To avoid matrix effects, they must generally be separated prior to their determinations. Covalent $\mathrm{HgBr}_{2}, \mathrm{SbBr}_{3}, \mathrm{AsBr}_{3}, \mathrm{GeBr}_{4}, \mathrm{SnBr}_{4}$ and $\mathrm{SeBr}_{4}$ can be extracted by non-polar organic solvents such as benzene or tetrachloromethane in the high concentration acid solution (such as $\mathrm{H}_{2} \mathrm{SO}_{4}$ or $\left.\mathrm{HClO}_{4}\right)^{1}$, so that these elements can be separated or preconcentrated from complex matrix. However, organic solvents extraction has big drawbacks such as toxicity and difficulty in automation for separation and subsequent determination. Therefore, other pretreated technique has been widely applied and developed for simultaneous determination of volatile elements ${ }^{2-4}$. Among those, solid phase extraction (SPE) technique has become one of the most popular techniques because it offers many advantages such as simplicity, no emulsification, low sample/reagent consumption and its ease in operation and ease in automation. Thus it is widely used for the separation/ preconcentration of trace metals ${ }^{5-8}$. However, for SPE technique, the selection of sorbent is very important. Usually, titanium dioxide ${ }^{9}$, single-walled carbon nanotubes ${ }^{10}$, ion-imprinted amino-functionalized silica ge ${ }^{11}$, Polyurethane foam $^{12}$, etc. were used as sorbent materials for $\mathrm{Hg}$ or $\mathrm{Sb}$, but those sorbent materials were ligands trapped in or chemically bonded to solid supports through complexing agent such as ammonium pyrrolidinedithiocarbamate (APDC) $)^{10,12,13}$, imprinted diazoaminobenzene-vinylpyridine copolymers ${ }^{14}$, forming hydrophobic complexes, which can be retained on a hydrophobic collection media.

In this paper, Amberlite XAD-16 resin was selected as the sorbent material for $\mathrm{Hg}$ and $\mathrm{Sb}$ not only because of its strong chemical resistance, high mechanical stability and high surface area but also its non-polar, which is similar to covalent 
$\mathrm{HgBr}_{2}$ and $\mathrm{SbBr}_{3}$. The applications based on the retention of halogen complexes on Amberlite XAD-16 resin are limited for the isolation of trace metal ions from matrix components ${ }^{15,16}$. The XAD-16 resin absorbs $\mathrm{HgBr}_{2}$ and $\mathrm{SbBr}_{3}$ through van der Waals force, which avoids the use of organic complexing agent.

To further prove the feasibility of proposed SPE method, in this study, the experiment was carried out on the separation of $\mathrm{Hg}$ and $\mathrm{Sb}$ from certified reference materials of lead-base alloys in $\mathrm{HBr}$ and concentrated $\mathrm{H}_{2} \mathrm{SO}_{4}$ and XAD-16 resin was used as the adsorbent. In this proposed method, SPE coupled with $\mathrm{HG}-\mathrm{DC}$-AFS to determine $\mathrm{Hg}$ and $\mathrm{Sb}$, the matrix $\mathrm{Pb}, \mathrm{Cu}$, $\mathrm{Sn}$ and $\mathrm{Bi}$ should be removed as completely as possible before entering HG-AFS and severe matrix induced signal interference and system contamination would be avoided. The optimum conditions for retention and elution were also discussed.

\section{EXPERIMENTAL}

The reagents used in this study were of analytical reagent grade or better. Ultrapure water of $18.2 \mathrm{M} \Omega \mathrm{cm}$ produced from the Milli-Q Plus system (Millipore, Bedford, MA, USA) was used for preparing all solutions. Mercury(II) and Sb(III) stock solution of $1 \mathrm{mg} \mathrm{mL}^{-1}$ were supplied by National Analytical Test Center of Nonferrous Metal and Electronic Material (Beijing, China). All analytical standard solutions were prepared by diluting the stock solution to the required concentration just before use. Concentrated $\mathrm{H}_{2} \mathrm{SO}_{4}$ (Beijing Chemical Factory, Beijing, China) was purified by column adsorption with the XAD-16 resin, ensuring the elimination of $\mathrm{Hg}$ (II), $\mathrm{Sb}$ (III) and other hydride forming elements (As, Bi, Ge, Sn, Se and $\mathrm{Pb}$ ) which could cause interference for analyzed elements. The eluent and carrier dilute $\mathrm{HCl}$ was diluted from concentrated $\mathrm{HCl}$ (Beijing Chemical Factory, Beijing, China). Hydrobromic acid was purchased from China Medicine Company (Beijing, China). $\mathrm{KBH}_{4}$ solution $[1.5 \%(\mathrm{~m} / \mathrm{v})$ ] was prepared by dissolving $\mathrm{KBH}_{4}$ (Tianjin Guangfu Research Institute for Fine Chemical Engineering, Tianjing, China) in $0.5 \%(\mathrm{~m} / \mathrm{v}) \mathrm{NaOH}$ (China Medicine Company, Beijing, China). Certified reference materials of lead-bade alloys (GBW02401, GBW02402) were obtained from Shanghai Institute of Materials (Shanghai, China).

A double channel atomic fluorescence spectrometer (AFS8220, Beijing Titan Instrument Co. Ltd., Beijing, China) was used. The optimal instrumental operating parameters were as follows: The negative high voltage of photomultiplier tube, $270 \mathrm{~V}$; the argon carrier gas and argon auxiliary gas flow rates

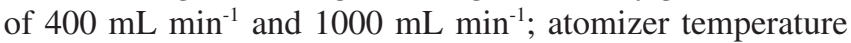
and height, $200{ }^{\circ} \mathrm{C}$ and $10 \mathrm{~mm}$; the currents of hollow cathode lamp, $60 \mathrm{~mA}$ for $\mathrm{Sb}$ and $15 \mathrm{~mA}$ for $\mathrm{Hg}$; detecting method, std. curve; signal recording mode, peak area; measurement time, $10 \mathrm{~s}$; delay time, $3 \mathrm{~s}$. Which had been recommended by the instrumental manufacture. High performance mercury (sensitive line $253.7 \mathrm{~nm}$ ) and antimony (sensitive line $217.6 \mathrm{~nm}$ ) hollow cathode lamp (Beijing General Research Institute for Non-Ferrous Metals, Beijing, China) were used as the radiation source. A Model FIA-3110 flow injection analysis system (Beijing Titan Instrument Co. Ltd., Beijing, China) was employed throughout the experiment. Special black viton pump tubes with resistance for strong acid erosion $(1.52 \mathrm{~mm}$ id.) were used to propel the samples and eluent and many white/black tubes (PTFE, $1.0 \mathrm{~mm}$ id.) were used for other solution pipeline.

Resin and column preparation: Amberlite XAD-16 resin (particle size, 20-40 mesh; Sigma Chem. Co., St. Louis) must be pretreated successively with ethanol, water, $5 \%$ (v/v) $\mathrm{HCl}$, water, $2 \%(\mathrm{~m} / \mathrm{v}) \mathrm{NaOH}$ and water, respectively, for eliminating rudimental unpolymerized monomer, dispersant, antiseptic and other baneful substances.

A short column with an inner diameter of $5 \mathrm{~mm}$ and a length of $80 \mathrm{~mm}$, equipped with porous rubbery plug, was filled up to a height of about $50 \mathrm{~mm}$ with about $200 \mathrm{mg}$ Amberlite XAD-16 resin by the dry packing method. To avoid the loss of filling when the sample solution passed, a small amount of quartz wool was placed at both ends of the column. Prior to use, $10 \%(\mathrm{v} / \mathrm{v}) \mathrm{HCl}$ solution, water and $10 \mathrm{~mol} \mathrm{~L}^{-1}$ $\mathrm{H}_{2} \mathrm{SO}_{4}$ solution were passed through the column in sequence in order to clean and condition it.

Sample pretreatment: A total of $10 \mathrm{mg}$ of certified standard reference materials (GBW02401, GBW02402) was weighed into a $100 \mathrm{~mL}$ beaker and decomposed with $2 \mathrm{~mL}$ concentrated $\mathrm{HCl}$ and $2 \mathrm{~mL}$ concentrated $\mathrm{HNO}_{3}$. This solution was transferred to a $100 \mathrm{~mL}$ volumetric flask and made up to volume with water, then, $100 \mu \mathrm{L}$ of this obtained solution was transferred to a $10 \mathrm{~mL}$ volumetric flask and $20 \mathrm{mmol} \mathrm{L}^{-1} \mathrm{HBr}$ was added for pre-reduction $0.5 \mathrm{~h}$, more $\mathrm{H}_{2} \mathrm{SO}_{4}$ was added to adjust the sample acidity to about $10 \mathrm{~mol} \mathrm{~L}^{-1}$. The resulted solution was then ready for subsequent separation and determination.

Analytical procedures: The sample solution of $5 \mathrm{~mL}$ was pumped through the SPE column at a flow rate of $1 \mathrm{~mL} \mathrm{~min}^{-1}$, $\mathrm{Hg}$ (II) and $\mathrm{Sb}$ (III) was then loaded onto the resin. To remove the matrix lead and other metals completely, $10 \mathrm{~mol} \mathrm{~L}^{-1} \mathrm{H}_{2} \mathrm{SO}_{4}$ blank solution was subsequently introduced to wash the SPE column and the pipe line at a flow rate of $3 \mathrm{~mL} \mathrm{~min}^{-1}$ for 100 $\mathrm{s}$. Then the retained analyte ions were eluted by $2 \mathrm{~mL}$ of $10 \%$ $(\mathrm{v} / \mathrm{v}) \mathrm{HCl}$ at a flow rate of $0.6 \mathrm{~mL} \mathrm{~min}{ }^{-1}$. Finally, $1.5 \%(\mathrm{~m} / \mathrm{v})$ $\mathrm{KBH}_{4}$ in $0.5 \%(\mathrm{~m} / \mathrm{v}) \mathrm{NaOH}$ was pumped to merge with the eluent, immediately, the target ions would react with $\mathrm{KBH}_{4}$ on line and the generated gas subsequently enter into atomic fluorescence spectrometry and were determined.

\section{RESULTS AND DISCUSSION}

Effect of $\mathrm{H}_{2} \mathrm{SO}_{4}$ and $\mathrm{HBr}$ concentration: In the present SPE procedure, sample acid concentration affects the sorption efficiencies of the covalent $\mathrm{HgBr}_{2}$ and $\mathrm{SbBr}_{3}$ onto the microcolumn. A series of solutions containing $10 \mu \mathrm{g} \mathrm{L}^{-1}$ of $\mathrm{Hg}$ (II) and $\mathrm{Sb}(\mathrm{III})$ were prepared at different $\mathrm{H}_{2} \mathrm{SO}_{4}$ concentrations. These solutions were loaded on the SPE column, while both $\mathrm{Hg}$ (II) and $\mathrm{Sb}$ (III) in the effluent liquid were monitored. The adsorption percentage of $\mathrm{Hg}$ (II) and $\mathrm{Sb}$ (III) in different $\mathrm{H}_{2} \mathrm{SO}_{4}$ concentrations was shown in Fig. 1, which revealed that the adsorption of $\mathrm{Hg}$ (II) and $\mathrm{Sb}$ (III) increased with the increase of the $\mathrm{H}_{2} \mathrm{SO}_{4}$ concentration and reached a peak at $10 \mathrm{~mol} \mathrm{~L}^{-1}$, then decreased sharply. The reason is that at higher concentrations of $\mathrm{H}_{2} \mathrm{SO}_{4}$, the formation of covalent molecular $\mathrm{HgBr}_{2}$ and $\mathrm{SbBr}_{3}$ becomes much easier, which causes the sorption 
efficiencies of non-polar resin XAD-16 for $\mathrm{HgBr}_{2}$ and $\mathrm{SbBr}_{3}$ become much higher. However, a large amount of heat will be produced in procedures of sample pretreatment and subsequent elution, which may cause volatilization losing of target ions and a cutoff of micropipette tips of micro-column while the concentration of $\mathrm{H}_{2} \mathrm{SO}_{4}$ was higher than $10 \mathrm{~mol} \mathrm{~L}^{-1}$, which caused the adsorption percentage of $\mathrm{Hg}(\mathrm{II})$ and $\mathrm{Sb}(\mathrm{III})$ decrease (Fig. 1). Thus, $10 \mathrm{~mol} \mathrm{~L}^{-1}$ was selected as the optimal concentration of $\mathrm{H}_{2} \mathrm{SO}_{4}$.

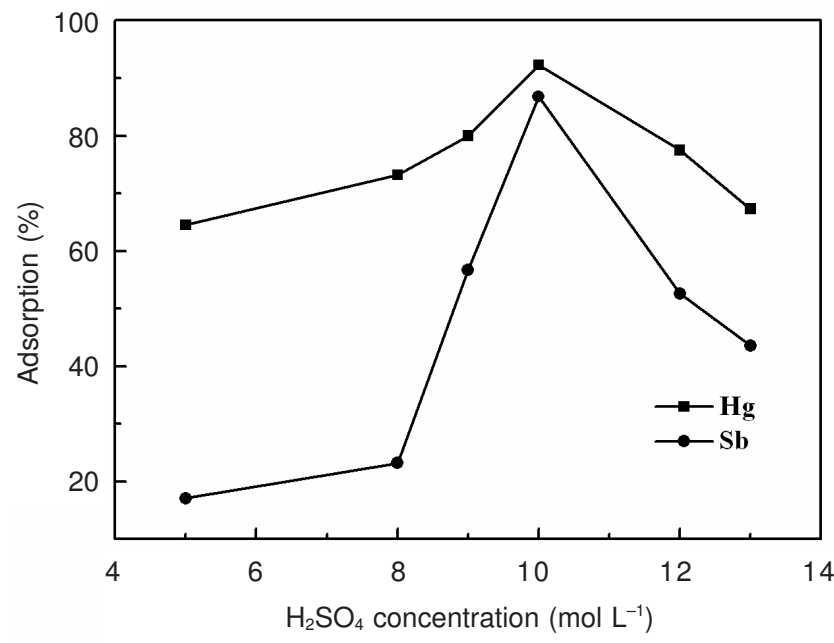

Fig. 1. Effect of $\mathrm{H}_{2} \mathrm{SO}_{4}$ concentration on adsorptions of $\mathrm{Hg}(\mathrm{II})$ and $\mathrm{Sb}$ (III). $\mathrm{Hg}(\mathrm{II})$ and $\mathrm{Sb}$ (III) $10 \mu \mathrm{g} \mathrm{L}^{-1}$; $\mathrm{HBr}$ concentration $20 \mathrm{mmol} \mathrm{L}^{-1}$; sample flow rate, $1.0 \mathrm{~mL} \mathrm{~min}^{-1}$; sample volume $5 \mathrm{~mL}$; tube washing, 10 $\mathrm{mol} \mathrm{L}^{-1} \mathrm{H}_{2} \mathrm{SO}_{4}$ at flow rate of $3.0 \mathrm{~mL} \mathrm{~min}^{-1}$ for $100 \mathrm{~s}$; elution, $2 \mathrm{~mL}$ $10 \%(\mathrm{v} / \mathrm{v}) \mathrm{HCl}$ at flow rate of $0.6 \mathrm{~mL} \mathrm{~min}^{-1}$

In real samples, antimony has two species $\mathrm{Sb}(\mathrm{V})$ and $\mathrm{Sb}(\mathrm{III})$, so, the importance of selecting suitable pre-reduction procedures to quantitatively convert $\mathrm{Sb}(\mathrm{V})$ to $\mathrm{Sb}$ (III) should not be disregarded. Pre-reduction of the species has mostly been achieved by the addition of iodide or bromide, L-cysteine and thioure $\mathrm{a}^{17}$. In this work, $\mathrm{HBr}$ was selected not only because it can be used as reducing agent but also it was source of anion $\mathrm{Br}^{-}$in covalent compounds $\mathrm{HgBr} 2$ and $\mathrm{SbBr} 3$. Thus, $\mathrm{HBr}$ concentration of 5, 10, 20, 30, 40 and $50 \mathrm{mmol} \mathrm{L}^{-1}$ were tested to observe their effects on the adsorption percentage of target ions. Fig. 2 showed that the adsorption of $\mathrm{Hg}$ (II) changed slowly with the increase of the $\mathrm{HBr}$ concentration. However, the adsorption of $\mathrm{Sb}$ (III) changed dramatically. For antimony, the concentration of $\mathrm{HBr}$ directly affects the pre-reduction of $\mathrm{Sb}(\mathrm{V})$, the content of $\mathrm{Sb}(\mathrm{III})$ will increase with the increase of the $\mathrm{HBr}$ concentration, which accordingly indicated that the adsorption of $\mathrm{Sb}$ (III) increased at the beginning in Fig. 2. But excessive high concentration of $\mathrm{HBr}$ will cause the formation of $\mathrm{Br}_{2}$ in concentrated $\mathrm{H}_{2} \mathrm{SO}_{4}$, which will be absorbed by XAD16 resin while through the column because of the non-polar of $\mathrm{Br}_{2}$. In actual experiment, the color of the liquid became deep brown and the resin became yellow when through column at the higher concentration of $\mathrm{HBr}$. This must lead to the reduction of adsorption percentage of target ions. But the adsorption percentage reached a peak at $20 \mathrm{mmol} \mathrm{L}^{-1}$ for both target ions, which was selected as the optimal concentration of $\mathrm{HBr}$.

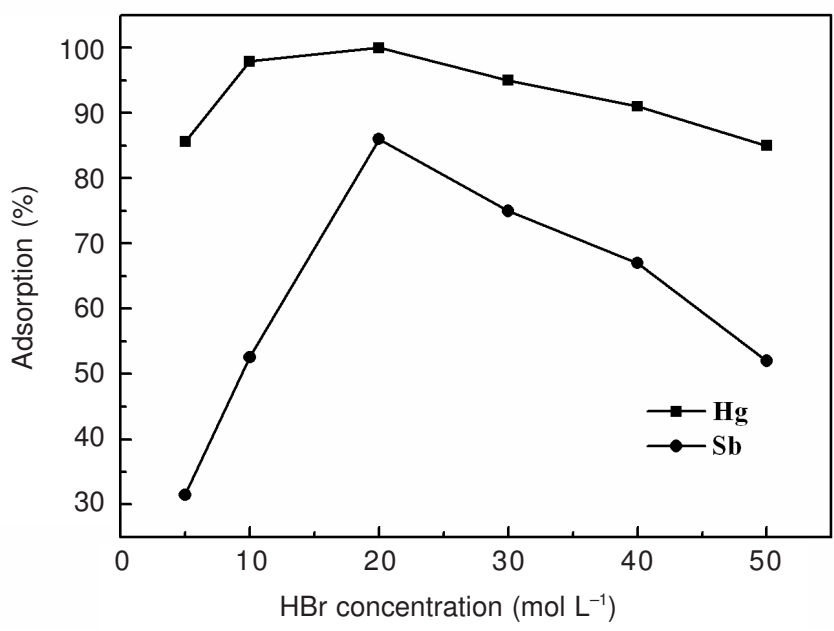

Fig. 2. Effect of $\mathrm{HBr}$ concentration on adsorptions of $\mathrm{Hg}(\mathrm{II})$ and $\mathrm{Sb}$ (III). $\mathrm{Hg}$ (II) and $\mathrm{Sb}(\mathrm{III}) 10 \mu \mathrm{g} \mathrm{L}^{-1}$ in $10 \mathrm{~mol} \mathrm{~L}^{-1} \mathrm{H}_{2} \mathrm{SO}_{4}$; other conditions, the same as in Fig. 1

Effect of sample flow rates: Sample flow rate is very important not only for throughout of batches samples, flow injection procedure but also the recoveries of target elements. Thus, the influence of the sample flow rate ranging from 0.2 to $4 \mathrm{~mL} \mathrm{~min}^{-1}$ was studied when $\mathrm{Hg}$ (II) and $\mathrm{Sb}$ (III) solution of $10 \mu \mathrm{g} \mathrm{L}^{-1}$ in $10 \mathrm{~mol} \mathrm{~L}^{-1} \mathrm{H}_{2} \mathrm{SO}_{4}$ was loaded on the SPE column and other factors were kept constant. As can be seen from (Fig. 3), both the recoveries of $\mathrm{Hg}$ (II) and $\mathrm{Sb}$ (III) increased firstly then decreased with the increasing of flow rates and reached to highest at the flow rate of $1 \mathrm{~mL} \mathrm{~min}^{-1}$. The reason is possibly that the acting force between $\mathrm{HgBr}_{2}, \mathrm{SbBr}_{3}$ and $\mathrm{XAD}-16$ resin is van der Waals force, which is very weak. When the sample flow rate is too high, the $\mathrm{HgBr}_{2}$ and $\mathrm{SbBr}_{3}$, not yet adsorbed entirely by resin, will discharge from the end of micro-column. And an over high flow rate could generate high back-pressure inside the packed micro-column employed in the flow injection systems, thus leading sample leakage at the connections between the micropipette tips of the microcolumn and the pipeline of flow injection system ${ }^{18}$. In order to enhance the sample throughout and to limit the total flow rate through the micro-column, a sample flow rate of $1 \mathrm{~mL} \mathrm{~min}^{-1}$ were selected as optimal values.

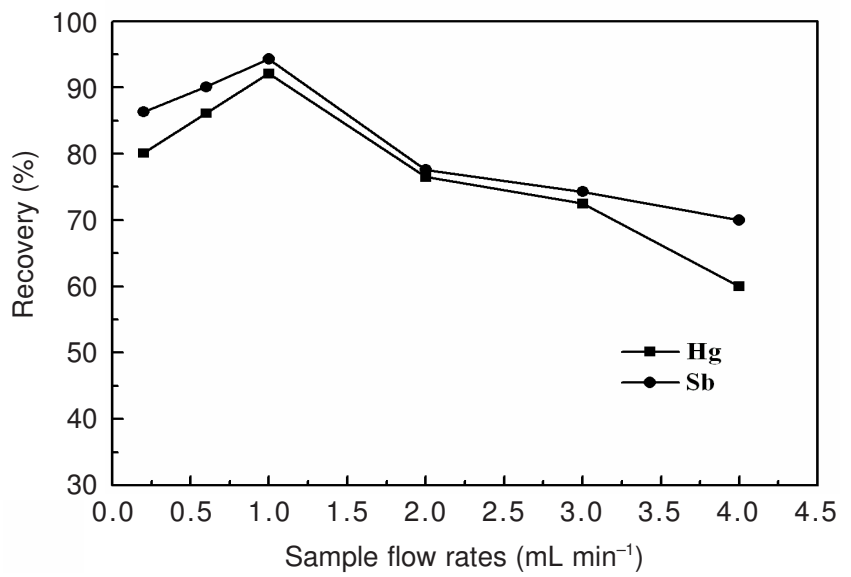

Fig. 3. Effect of sample flow rates on the recoveries of target elements. $\mathrm{Hg}(\mathrm{II})$ and $\mathrm{Sb}(\mathrm{III}) 10 \mu \mathrm{g} \mathrm{L}^{-1}$ in $10 \mathrm{~mol} \mathrm{~L}^{-1} \mathrm{H}_{2} \mathrm{SO}_{4}$; other conditions, the same as in Fig. 1 
Effect of eluent type, flow rates and elution volume: For nonpolar $\mathrm{SbBr}_{3}$ and $\mathrm{HgBr}_{2}$, according to the similar properties, the non-polar eluent such as benzene or tetrachloromethane should be selected. But, an appropriate eluent should not only ensure an effective elution of the absorbed analytes but also provide a favorable medium for the subsequent hydride generation. And these organic reagents are not suitable for the subsequent analysis by HG-AFS. For this reason, $0.1,0.2,0.5,1.0,1.5,2,5,10,15,20$ and $30 \%(\mathrm{v} / \mathrm{v}) \mathrm{HNO}_{3}$ and $\mathrm{HCl}$, commonly used as the acid medium for hydride generation, were selected and tested as eluent with the flow rate fixed at $1 \mathrm{~mL} \mathrm{~min}^{-1}$. The results showed that for $\mathrm{HNO}_{3}$, even at the concentration of $30 \%(\mathrm{v} / \mathrm{v})$, the recoveries of $\mathrm{Hg}$ (II) was always lower than $10 \%$ and for $\mathrm{Sb}(\mathrm{III})$, when the concentration of $\mathrm{HNO}_{3}$ was $10 \%(\mathrm{v} / \mathrm{v})$, the recovery reached to highest of $30 \%$. But for $\mathrm{HCl}$, the recoveries of target elements were both higher than $30 \%$ in the range of concentration. So, $\mathrm{HCl}$ was selected as the eluent of both target ions. With the increase of the $\mathrm{HCl}$ concentration, The recovery of $\mathrm{Hg}$ (II) and $\mathrm{Sb}$ (III) were increased too and reached to highest of $98.3 \%$ and $94.2 \%$ at the concentration of $10 \%(\mathrm{v} / \mathrm{v})$ and $5 \%(\mathrm{v} / \mathrm{v})$ for $\mathrm{Hg}(\mathrm{II})$ and $\mathrm{Sb}$ (III), respectively. Meanwhile, the recovery was $85 \%$ for $\mathrm{Sb}$ (III), $52.3 \%$ for $\mathrm{Hg}$ (II) at the concentration of $10 \%$ (v/v) and $5 \%(\mathrm{v} / \mathrm{v}) \mathrm{HCl}$, respectively. To compromise both target ions $10 \%(\mathrm{v} / \mathrm{v}) \mathrm{HCl}$ was selected as eluent.

However, as can be seen in Figs. 4 and 5, both target analytes could be effective eluted at $0.6 \mathrm{~mL} \mathrm{~min}{ }^{-1}$ of eluent flow rate and $2 \mathrm{~mL}$ of elution volume for $10 \%$ (v/v) $\mathrm{HCl}$ When keeping other experimental factors constant. The reason perhaps is that excessive $\mathrm{Cl}^{-}$in $\mathrm{HCl}$ can be combined to $\mathrm{Hg}(\mathrm{II})$ and $\mathrm{Sb}(\mathrm{III})$, then form complex ions of $\left[\mathrm{HgCl}_{4}\right]^{2-}$ and $\left[\mathrm{SbCl}_{4}\right]^{-}$, which are polar compounds, so facilitating the stripping of target ions from non-polar resin XAD-16, thus the elution effect of $\mathrm{HCl}$ on $\mathrm{Hg}$ (II) and $\mathrm{Sb}$ (III) are better than $\mathrm{HNO}_{3}$. But, $\mathrm{Cl}^{-}$can not adequately compete to strong covalent bond between target ions and $\mathrm{Br}^{-}$when flow rate of $\mathrm{HCl}$ is quick and elution volume is small. So, the flow rate of $0.6 \mathrm{~mL} \mathrm{~min}{ }^{-1}$ and elution volume of $2 \mathrm{~mL}$ were finally selected in this method.

Interferences of coexisting ions in matrix: For real sample analysis, the determination of $\mathrm{Hg}$ and $\mathrm{Sb}$ could be easy

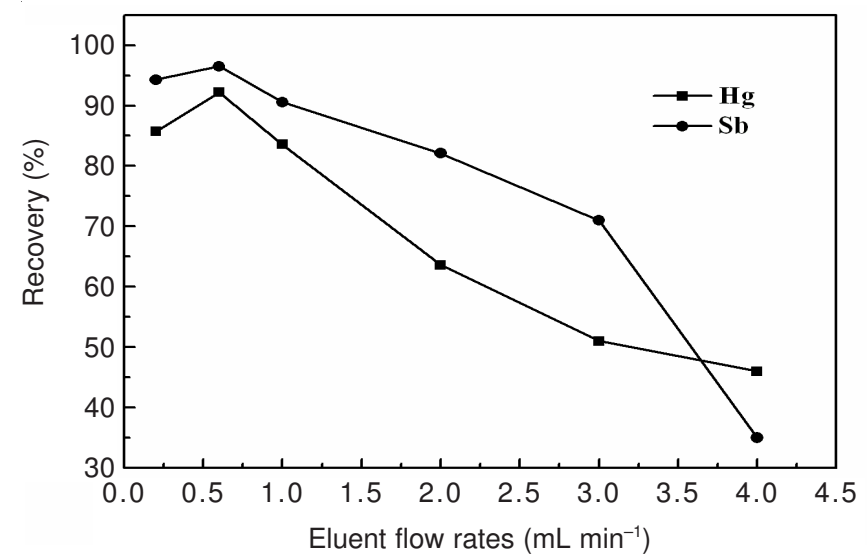

Fig. 4. Effect of eluent flow rates on the recoveries of target elements. $\mathrm{Hg}$ (II) and $\mathrm{Sb}$ (III) $10 \mu \mathrm{g} \mathrm{L}{ }^{-1}$ in $10 \mathrm{~mol} \mathrm{~L}^{-1} \mathrm{H}_{2} \mathrm{SO}_{4}$; other conditions, the same as in Fig. 1

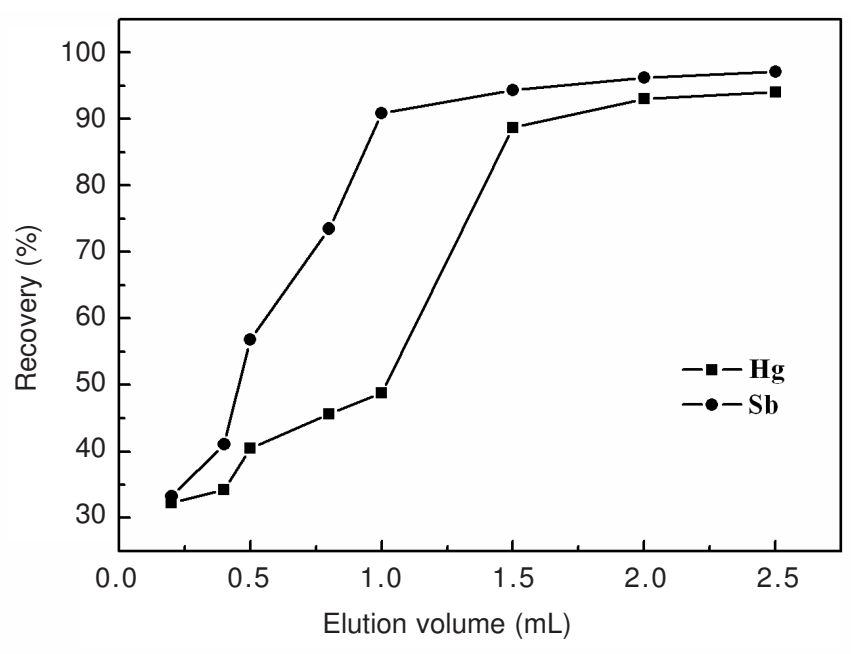

Fig. 5. Effect of elution volume on the recoveries of target elements. $\mathrm{Hg}$ (II) and $\mathrm{Sb}$ (III) $10 \mu \mathrm{g} \mathrm{L}^{-1}$ in $10 \mathrm{~mol} \mathrm{~L}^{-1} \mathrm{H}_{2} \mathrm{SO}_{4}$; other conditions, the same as in Fig. 1

affected by the sample matrix. But an essential advantage of SPE method coupled with hydride generation techniques is the separation of the analyte from the matrix, which eliminates the effects of the most common matrix constituents in the examined real samples including alkali and alkaline earth elements ${ }^{19,20}$. Although, potential interferents mainly come from transition metals, heavy metals and other hydride forming elements ${ }^{21-24}$ that could interfere with $\mathrm{Hg}$ and $\mathrm{Sb}$ determination or present in alloy samples were tested. For this experiment, $5 \mathrm{~mL}$ of the solution containing $10 \mu \mathrm{g} \mathrm{L}^{-1} \mathrm{Hg}$ and $\mathrm{Sb}$ and various amounts of interfering ions (Table-1) were treated with the whole analytical procedure. The tolerance limits $\left(\mu \mathrm{g} \mathrm{L}^{-1}\right)$ was defined as interferent concentration varying the analyte signals by $10 \%$. As can be seen from Table-1, the tolerable concentration of $\mathrm{Pb}$ were higher than other elements owing to the formation of $\mathrm{PbSO}_{4}$ precipitation which would be separated from other solution ions in $\mathrm{H}_{2} \mathrm{SO}_{4}$ medium and the tolerable concentration of other hydride forming elements were lower because of their similar properties with $\mathrm{Hg}$ and $\mathrm{Sb}$. These matrix constituents in real alloys samples and residual reagents could be eliminate through washing the column before elution, which meant that the interference from the matrices and co-existing ions can be ignored.

\begin{tabular}{ccc} 
TABLE-1 \\
INTERFERENCE EVALUATION OF COEXISTING IONS IN \\
TERMS OF TOLERANCE LIMITS \\
\hline \multirow{2}{*}{ Tons } & $\mathrm{Hg}$ & $\mathrm{Sb}$ \\
\cline { 2 - 3 } $\mathrm{Fe}$ & 150 & 100 \\
$\mathrm{Zn}, \mathrm{Ni}$ & 90 & 80 \\
$\mathrm{Cu}, \mathrm{Cd}$ & 80 & 80 \\
$\mathrm{~Pb}$ & 1000 & 1000 \\
$\mathrm{Sn}$ & 160 & 150 \\
$\mathrm{Bi}, \mathrm{As}$ & 50 & 50 \\
\hline
\end{tabular}

Column reuse: The stability and regeneration of the column are the key factors in evaluating the performance of a robust SPE system. They were verified of the XAD-16 packed micro-column in this study and the results showed the column 
TABLE-2

RESULTS OF RECOVERIES AND REAL SAMPLE ANALYSIS ${ }^{\mathrm{a}}($ MEAN VALUE \pm STANDARD DEVIATION, $\mathrm{n}=3$ )

\begin{tabular}{|c|c|c|c|c|c|c|c|}
\hline \multirow{2}{*}{ Samples } & \multicolumn{2}{|c|}{ Added $\left(\mu \mathrm{g} \mathrm{L}^{-1}\right)$} & \multicolumn{2}{|c|}{ Certified $\left(\mu \mathrm{g} \mathrm{L}^{-1}\right)$} & \multicolumn{2}{|c|}{ Found $\left(\mu \mathrm{g} \mathrm{L}^{-1}\right)$} & \multirow{2}{*}{$\begin{array}{c}\text { Recoveries \% } \\
\mathrm{Sb} \\
\end{array}$} \\
\hline & $\mathrm{Hg}$ & $\mathrm{Sb}$ & $\mathrm{Sb}$ & $\mathrm{Hg}$ & $\mathrm{Sb}$ & $\mathrm{Hg}$ & \\
\hline CRW02401 & 0 & 0 & $160.9 \pm 1.0$ & - & $152.6 \pm 2.6$ & - & 94.84 \\
\hline GBW02401 & 20 & 20 & - & $21.12 \pm 0.8$ & $179.5 \pm 3.1$ & 105.6 & 99.23 \\
\hline GBW02402 & 0 & 0 & $150.2 \pm 0.6$ & - & $136.2 \pm 3.9$ & 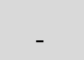 & 90.68 \\
\hline & 20 & 20 & - & $20.02 \pm 0.9$ & $162.9 \pm 2.8$ & 100.1 & 95.71 \\
\hline
\end{tabular}

a. All data are about solution sample analysis and the sample solutions were prepared according to the sample pretreatment part;

was stable with long lifetime, enabling more than 20 separation/ elution cycles to be performed with no significant effect on both $\mathrm{Hg}$ and $\mathrm{Sb}$ fluorescence signals. After experiment, the column can be dealed with successively as follow, rinsed with ethanol, $2 \%(\mathrm{v} / \mathrm{v}) \mathrm{HCl}$, water, $2 \%(\mathrm{~m} / \mathrm{v}) \mathrm{NaOH}$ and water for regeneration and reuse for the next experiment.

Analytical performances and real samples analysis: Linear calibrations curves were obtained by intensity of the elution after separation against the concentration of the corresponding target ions before separation solution. The calibration curves were linear in the range of $0.2-50 \mu \mathrm{g} \mathrm{L}^{-1}$ and $2-500 \mu \mathrm{g}$ $\mathrm{L}^{-1}$ with a correlation coefficient of 0.9994 and 0.9935 for $\mathrm{Hg}(\mathrm{II})$ and $\mathrm{Sb}(\mathrm{III})$, respectively, the calibration equation were: $\mathrm{y}=187.81+214.48 \mathrm{x}$ for $\mathrm{Hg}(\mathrm{II})$ and $\mathrm{y}=12.93+0.54 \mathrm{x}$ for $\mathrm{Sb}$ (III), where $\mathrm{y}$ was the intensity and $\mathrm{x}$ was the concentration of $\mathrm{Hg}$ (II) and $\mathrm{Sb}$ (III) expressed in $\mu \mathrm{g} \mathrm{L}^{-1}$. The limits of detection (LODs), calculated to be three times the standard deviation of 10 blank measurements, were $0.17 \mu \mathrm{g} \mathrm{L}^{-1}$ and $1.66 \mu \mathrm{g} \mathrm{L}^{-1}$ for $\mathrm{Hg}$ (II) and $\mathrm{Sb}$ (III), respectively. The RSD of a standard solution containing $20 \mu \mathrm{g} \mathrm{L}^{-1}$ of $\mathrm{Hg}$ (II) and $\mathrm{Sb}$ (III) for 7 measurements were $0.37 \%$ for $\mathrm{Hg}$ and $2.90 \%$ for $\mathrm{Sb}$, respectively. Spiked test and the analysis of certified standard reference materials were also performed for method validation. The obtained quantitative results were shown in Table-2. As the results revealed, The recoveries for $20 \mu \mathrm{g} \mathrm{L}{ }^{-1} \mathrm{Hg}$ (II) spiked and $\mathrm{Sb}$ (III) in certified standard reference materials solution were in the range of 90.68-105.60\%.

\section{Conclusion}

A novel green solid phase extraction method coupled with hydride generation-double channel atomic fluorescence spectrometry was established to separate/preconcentrate and determine the $\mathrm{Hg}$ and $\mathrm{Sb}$ in the form of non-polar inorganic covalent compounds $\mathrm{HgBr}_{2}$ and $\mathrm{SbBr}_{3}$ by using XAD-16 resins columns. The application of the procedure proposed showed that mercury and antimony can be effectively separated/preconcentrated from lead-base alloy on Amberlite XAD-16 resin columns. Obviously, The developed method, which is low cost, easy operation, may be used for the separation/preconcentration of trace $\mathrm{Hg}$ and $\mathrm{Sb}$ in other samples with various matrix compositions, such as other metals-base alloys like aluminium-base alloy, tin-base alloy, zinc-base alloy which require a high concentration of acid to decompose and also geological materials, natural water samples, etc.

\section{ACKNOWLEDGEMENTS}

This work was financially supported by National Natural Science Foundation of China (20975099) and Science and Study Project for Doctor of Jilin Normal University ( 2012001).

\section{REFERENCES}

1. C.S. Zhou, Chemical Separation-Concentration and Their Application, Central South University of Technology Press, Changsha, p. 255 (1997).

2. M. Elsayed, E. Bjorn and W. Frech, J. Anal. At. Spectrom., 15, 697 (2000).

3. L. Pszonicki and J. Dudek, J. Anal. At. Spectrom., 14, 1755 (1999).

4. R.M. Camero and R.E. Sturgeon, Spectrochim. Acta B, 54, 753 (1999).

5. C.M. Andrle, N. Jakubowski and J.A.C. Broekaert, Spectrochim. Acta B, 52, 189 (1997).

6. X.H. Shang and X.P. Yan, J. Anal. At. Spectrom., 22, 1284 (2007).

7. V. Camel, Spectrochim. Acta B, 58, 1177 (2003).

8. B.B. Chen, S.J. Heng, H.Y. Peng, B. Hu, X. Yu, Z. Zhang, D. Pang, X. Yue and Y. Zhu, J. Anal. At. Spectrom., 25, 1931 (2010).

9. L. Zhang, D. Ishi, K. Shitou, Y. Morita and A. Isozaki, Talanta, 68, 336 (2005)

10. H. Wu, X.C. Wang, B. Liu, Y.L. Liu, S.S. Li, J.S. Lu, J.Y. Tian, W.F. Zhao and Z.H. Yang, Spectrochimi. Acta B, 66, 74 (2011).

11. H. Zheng, T.M. Geng and L.M. Hu, Chem. Anal., 53, 673 (2008).

12. S. Arpadjan, L. Vuchkova and E. Kostadinova, Analyst, 122, 243 (1997).

13. L. Vuchkova and S. Arpadjan, Talanta, 43, 479 (1996).

14. Y.W. Liu, X.J. Chang, D. Yang, Y. Guo and S. Meng, Anal. Chim. Acta, 538, 85 (2005).

15. L. Elçi, M. Soylak, A. Uzun, E. Büyükpatir and M. Dogan, Fresenius J. Anal. Chem., 368, 358 (2000).

16. X.L. Liu, T.C. Duan, Y. Han, X.Y. Jia and H.T. Chen, J. Anal. At. Spectrom., 25, 206 (2010).

17. Z.X. Li and Y.A. Guo, Talanta, 65, 1318 (2005)

18. H. Wu, H.Y. Wen, B.P. Han, B.X. Du, J.S. Lu and J.Y. Tian, Microchim. Acta, 166, 41 (2009).

19. M.L. Chen, Y.M. Huo and J.H. Wang, Talanta, 78, 88 (2009).

20. A.N. Anthemidis and E.K. Martavaltzoglou, Anal. Chim. Acta, 573, 413 (2006).

21. X.P. Yan, X.B. Yin, X.W. He and Y. Jiang, Anal. Chem., 74, 2162 (2002).

22. H. Wu, Y. Jin, Y. Tian, X.C. Tao and S.P. Bi, At. Spectrosc., 28, 220 (2007).

23. Z.X. Li and Y.A. Guo, Talanta, 65, 1318 (2005).

24. Z.X. Li, X.M. Yang, Y.A. Guo, H.T. Li and Y.H. Feng, Talanta, 74, 915 (2008). 